\title{
Epidermoid cyst: a rare intratesticular tumor in children
}

\author{
Ethan A. Smith • Jonathan R. Dillman
}

Received: 17 August 2009 / Accepted: 8 September 2009/Published online: 7 May 2010

(C) Springer-Verlag 2009

An 18-year-old boy presented with a palpable left testicular mass. Sonography demonstrated a circumscribed left intratesticular mass with concentric layers of alternating increased and decreased echogenicity (Fig. 1). There was no blood flow within the lesion with color Doppler interrogation (Fig. 2). Sonographic findings suggested a testicular epidermoid cyst, a diagnosis that was pathologically confirmed following surgical enucleation.

Epidermoid cysts are rare benign tumors with no malignant potential that compose $1-2 \%$ of intratesticular masses in children [1]. Histopathologically, these lesions are lined by stratified squamous epithelium and filled with

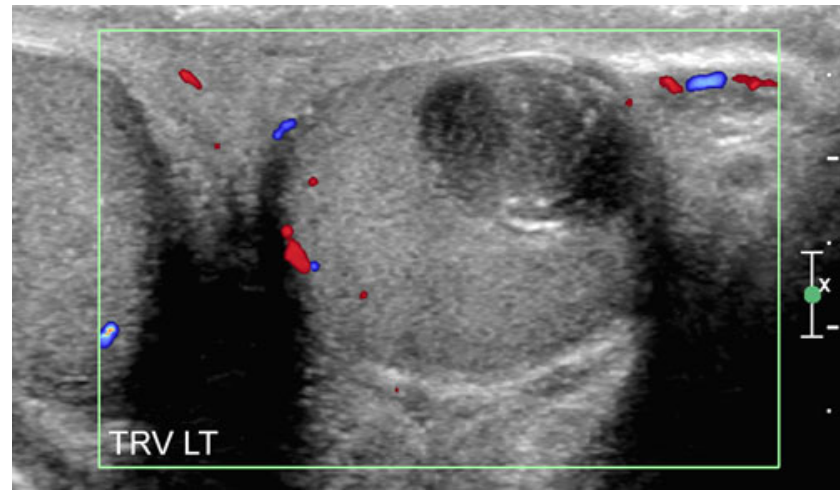

Fig. 2 Transverse color Doppler image of the left testicle

keratinous debris. Patients typically present with a palpable testicular mass that may or may not be painful $[1,2]$. Sonographically, these lesions appear as welldemarcated, avascular intra-testicular masses, frequently with an onion-skin appearance caused by lamellated keratinous debris [1]. While orchiectomy has been the historical treatment of choice, testicle-sparing enucleation of such lesions is now commonly performed.

\section{References}

1. Cho JH, Chang JC, Park BH et al (2002) Sonographic and MR imaging findings of testicular epidermoid cysts. AJR 178:743-748

2. Fujino J, Yamamoto H, Kisaki Y et al (2004) Epidermoid cyst: rare testicular tumor in children. Pediatr Radiol 34:172-174 